\title{
Holoprosencephalus with Cyclopia: A Case Report
}

\author{
Solomon Gebre ${ }^{* 1}$, Ephrem Tsehaye ${ }^{1}$, Ermias Abate ${ }^{2}$ \\ ${ }^{I}$ Department of Integrated Emergency Surgery and Obstetrics Maiani General Hospital, Northern Ethiopia \\ ${ }^{2}$ Department of Obstetrics and Gynecology, Mekelle University Faculty of Medicine, Ayder Comprehensive \\ specialized hospital, Northern Ethiopia
}

*Corresponding Author: Solomon Gebre, Department of Integrated Emergency Surgery and Obstetrics Maiani General Hospital, Northern Ethiopia, E-mail: solomongebre300@gmail.com

\begin{abstract}
Background: Holoprosencephaly is a developmental defect of the embryonic forebrain, or prosencephalon that is commonly associated with midfacial defects. The defect results from incomplete development of central nervous system structure and has different spectrum including, Alobar, Semilobar, and lobar. Severe forms of holoprosencephaly are associated with severe facial midline defects, such as a primitive nasal structure (proboscis), cyclopia and midfacial clefting. The incidence is estimated 1:250 in spontaneous abortions during embryogenesis and 1:16,000 in live birth. Pathogenesis of holoprosencephaly is complex involving teratogenic exposures like Ethanol, genetic abnormalities and syundromic associations.Maternal Diabetic is a well-established associated risk factor with 200-fold increase the incidence.
\end{abstract}

Case presentation: This is a case report 28 years old Gravida 3 Para 2and no history abortion, with previous history of normal vaginal birth who present with compliant of absent of fetal movement for five days to referral outpatient department (OPD). Ultrasoundexamination confirms fetal demise and counseled for termination of the pregnancy. After the women induced with misoprostol per the hospital protocol she delivered a 2.2 kilogram dead male fetus at Maiani general hospital northern Ethiopia with multiple defects and diagnosed as case of holoprosecephaly with cyclopia.

Conclusion: - Even though holoprosencephaly is rare but it is commonest structural congenital anomaly of brain with complex and multifactorial pathogenesis. Early perinatal diagnosis and determining the degree of severity is important to inform the family if termination of pregnancy is indicated, as well discussion with parents the challenges of rising of their child incase prognosis is good or compatible with extra uterine life.

Keywords: Holoprosencephalus, Alobar, Cyclopia.

\section{INTRODUCTION}

Holoprosencephaly is a developmental defect of the embryonic forebrain, or prosencephalon that is commonly associated with midfacial defects $(1,2)$. The defect results from incomplete development of central nervous system structure and has different spectrum including, A lobar, Semilobar, and lobar.

Severe forms of holoprosencephaly are associated with severe facial midline defects, such as a primitive nasal structure (proboscis), cyclopia and midfacial clefting (3-6).

The incidence is estimated 1:250 in spontaneous abortions during embryogenesis and 1:16,000 in live birth. Pathogenesis of holoprosencephaly is complex involving teratogenicexposures like
Ethanol, genetic abnormalities and syundromic associations.

Maternal Diabetic is a well-established associated risk factor with 200 -fold increase the incidence (5-7).

\section{CASE PRESENTATION}

This is a case report 28 years old Gravida 3 Para 2 and no history abortion, with previous history of two normal vaginal birth both alive who present with compliant of absent of fetal movement for five days to referral outpatient department (OPD).

Ultrasound examination revealed in utero fetal death with microcephalus and gross polyhadraminus but the forebrain defect were not detected. This woman hade ANC follow up at 
nearby local health center twice and it was uninvent full, had no any chronic medical condition like diabetics and teratogenic exposures throughout the pregnancy period. All laboratory investigations were normal including serum glucose level.Parent was counseled for termination of the pregnancy,after the women were induced with misoprostol per the hospital protocol she delivered a 2.3 kilogram dead male fetus at Maiani general hospital northern Ethiopia with multiple defects and diagnosed as

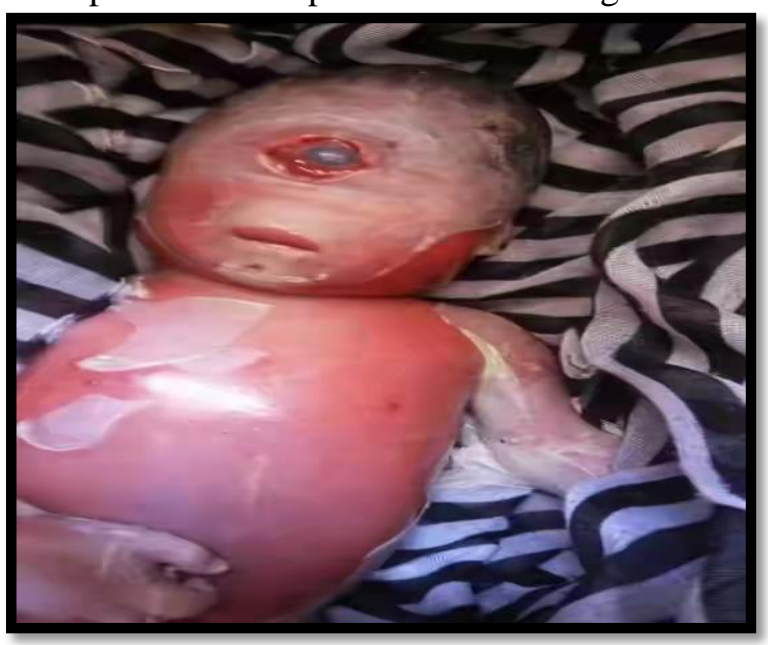

Figure1

\section{DISCUSSION}

This case report we presented is a unique case with severe form of holoprosecephaly with cyclopia diagnosed in the postnatal period in a neonate born in Maiani general hospital northern Ethiopia.

The exact cause of holoprosecephaly is left unknown but research revealed there are multiple risk factors including teratogenic exposures and genetic causes. Among the possible teratogenic exposures which shown increased risk factor in animal model includes long use of Aspirin, statins, poor glycemic control (hyperglycemia), methotrexate, and high alcohol consumption, which are yet to replicate in human $(1,2,3,4)$. However in the presented case the mother dines exposure to above risk factors. Bleeding during the first trimester of pregnancy and history of miscarriage in women could result in the birth of neonates with HPE; however, no significant correlation has been reported between the incidence of HPE and maternal age $(4,5)$.

TORCH infections in early pregnancy are potentially affect the neurological embryogenesis leading holoprosecephaly but in our case as much as possible infections were ruled out $(6,7)$.

An autosomal dominant inheritance is certainly existed but in rare case of holoprosecephaly. case of holoprosecephaly with cyclopia (Figure 1). In a gross postnatal neonatal examination, there was single midline located eye, but there was no nasal aperture or proboscis in the midline. Both ears externally were anatomically normal, no cleft lip or palate but there was migrognathia. All other organs gross examination was normal including the umbilical cord and the spine. Post mortem examination was not do because the service not available in hospital.

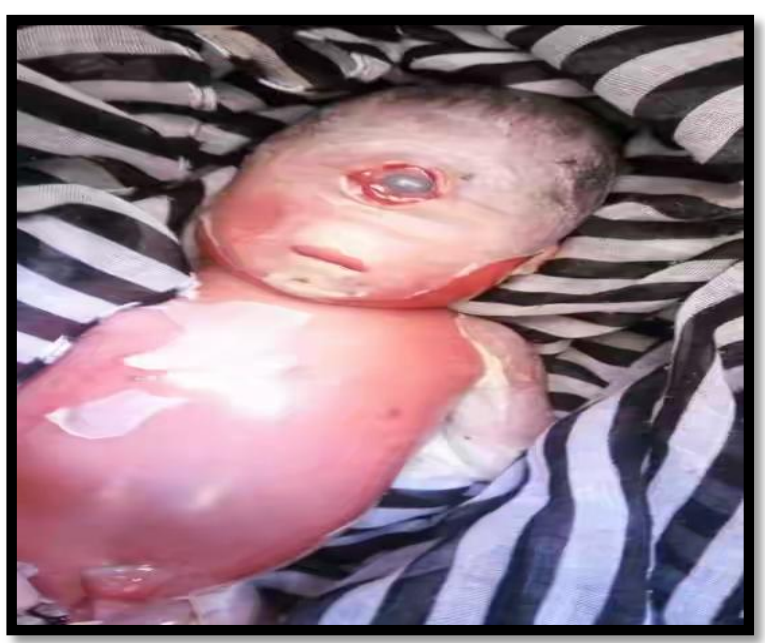

Trisomy 13 and 18 may be associated with cyclopia or possibly associated with other chromosomal abnormalities or occasionally with normal chromosomes $(6,7)$.

It arises commonly in the early period the gestational life causing lack of cleavage of the hemisphere in to right and left cerebral hemisphere. Neural tube forms three primary vesicles, the prosencephalon, mesencephalon and rhombencephalon as early as the first 4th gestational life. Prosencephalon further divided in to telencephalon and diencephalon in 5th gestational age. Failure of complete or partial division of developing prosencephalon in to hemispheres and lobes leads to this complex neural abnormality holoprosecephaly $(8,9,10)$.

Holoprosecephaly is diagnosed prenatally but needs high index of suspicion. However in our case diagnosis were not made despite the prenatal ultrasound examination, the prominent clinical manifestations of HPE are absence of the eyes, cebocephaly, cyclopia, proboscis, cheilo/palatoschisis and agnathia (i.e., severe micrognathia). Among these factors, cyclopia, proboscis and cheilo/palatoschisis are associated with the incidence of severe HPE (Cohen MM Jr. Holoprosencephaly: clinical, anatomic, and molecular dimensions. 
Microcephaly or macrocephaly in some cases is indicative of the presence of hydrocephaly. On the other hand, mental retardation is known to have a direct correlation with the severity of HPE.

Earliest diagnoses for a lobar, semi-lobar and lobar HPE are reported during weeks 9.5, 13 and 21 of pregnancy, respectively $(11,12,13)$.

\section{CONClusion}

Even though holoprosencephaly is rare but it is commonest structural congenital anomaly of the brain with complex and multifactorial pathogenesis. Early perinatal diagnosis and determining the degree of severity is important to inform the family if termination of pregnancy is indicated, as well discussion with parents the challenges of rising of their child incase prognosis is good or compatible with extra uterine life.

\section{REFERENCES}

[1] Chukuemaka .A, Cecil A. HoloprosencephalyIn A Nigerian Female: A Case Report. Nigerian Health Journal 2009;9(1) ;30-33.

[2] Mehrbanu. A, Akram S, Ashraf S.Alobarholo prosencephaly: A case report. journsal of nursing and midwifery science 2015 ; 4(2):7074.

[3] SrinivasaBabu CR, Vineel I, Prakash A, Kumar YR. Antenatally diagnosed alobarholoprosen cephaly: A report of two cases. CHRISMED J Health Res 2017; 4:283-5.
[4] Rathod S, Samal SK, Begum J. Holoprosencep haly with cyclopia: a rare case report. Int J Otorhinolaryngol Head Neck Surg 2015;1:37-9.

[5] V PATIL, K TAORI, N SARDESAI, V INGLE .Semi Lobar Holoprosencephaly- A Case Report.Ind J RadiolImag 2005 15:4:309-310.

[6] P Otuaga, AEweka, A Oni, L Ebite. Cyclops Deformity In Benin City, Nigeria: A Case Report. The Internet Journal of Neurology 2007:10(1); 1-4.

[7] Hong M, Krauss RS (2017) Ethanol itself is a holoprosencephaly-inducing teratogen. PLoS ONE 12(4): e0176440. https://doi.org/10.1371/

[8] Mircea O. POENARU, Ionut D. Holoprosence phaly : two case report.A Journal of Clinical Medicine, 2012:7(1):58-62.

[9] Pedro P, Frederick L, Paulina N.Semilobarholo prosencephaly in a 12- month-old baby boy born to a primigravida patient with type 1 diabetes mellitus: acase report. Journal of Medical Case Reports 2016; 10:358.

[10] .Folkerth RD, Lidov HCG. Congenital Malform ations, Perinatal Diseases, and Pharcomatoses. 2nd ed. Philadelphia: Elsevier; 2012. P.96-182.

[11] Birth Defects Res AClinMolTeratol 2006; 76(9):658-73.

[12] Kurtz AB, Wapner RJ, Rubin CS, Cole-Beuglet C, Ross RD, Goldberg BB. Ultrasound criteria for in utero diagnosis of microcephaly. J Clin Ultrasound 1980; 8(1):11-6.13.

[13] Keeling JW, Khong TY. Fetal and Neonatal Pathology. In: Boyd PA, Keeling JW. Congenital Abnormalities: Prenatal Diagnosis and Screening. 4th ed. Heidelberg: Springer; 2007.P.123-6.

Citation: Solomon Gebre, Ephrem Tsehaye, Ermias Abate. Holoprosencephalus with Cyclopia: A Case Report. ARC Journal of Pediatrics.2019; 5(1):11-13. doi:dx.doi.org/10.20431/2455-5711.0501004.

Copyright: (C) 2019 Authors. This is an open-access article distributed under the terms of the Creative Commons Attribution License, which permits unrestricted use, distribution, and reproduction in any medium, provided the original author and source are credited. 